\title{
Some Pedagogical Strategies and Approaches in L2 Acquisition: The Case of the Uzbek Language
}

\author{
Aziza Mashrabbekova \\ Associate Professor, Hankuk University of Foreign Studies, Seoul, South Korea
}

\begin{abstract}
This paper provides a pedagogical approach towards the teaching of Uzbek language. In sustaining my argument, I give a theoretical background to the research topic, as well as a critical analysis of teaching strategies of the language in question. The primary research aims to examine these pedagogical strategies towards using L2. This paper attempts to answer some pertinent issues on the teaching of L2 and specifically, the Uzbek language. To achieve this aim, I interrogate views on particular scholars who have put forward some pedagogical questions towards L2. For example, how factual is Halliday's point of view when he asserts that the teaching of a foreign language effectively to children is one of the hardest pedagogical tasks there is? (2007, 260). This is compounded by the fact that materials for instruction of the Uzbek language are sparse partly because of historical reasons which I briefly discuss.
\end{abstract}

This essay is not a comparative study of the Uzbek and Korean language. My emphasis is rather in the teaching of Uzbek as L2 to Korean students. Examples however will be drawn from both L1 and L2. In addition, it should be noted that some scholars, for example, Zanca (2007) mentions some Uzbek food but spells most of the lexical items in Russian as opposed to the way they are spelled in Uzbek. In this particular scenario, the words are left as such in Russian as spelled by Zanca (ibid) but alternative Uzbek spelling is provided in the footnote. There are however exceptions in his corpus. Orthographic system that I use in this paper is Latin based. In addition, this article does not use transliterations in concatenating phoneme sequences in Uzbek or Korean language.

Keywords: Pedagogy, Uzbek, Second Language Acquisition, Reinforcement, Turkic

\section{Geographical Position of Uzbekistan}

Uzbekistan is the most populous of the Central Asian countries, with 50 percent more people than Kazakhstan, its nearest competitor (Kort, 2016, 112). Uzbeks are the largest minority in Tajikistan, where they account for almost a quarter of the population.

In Kyrgyzstan, they account for 13.8 percent of the population, and in Turkmenistan, they make up more than 9 percent. Only in Kazakhstan, where their share of the population is only 2.5 percent, are Uzbeks a relatively insignificant group in terms of size. Uzbekistan, while smaller in area than both Kazakhstan and Turkmenistan, remains Central Asia's geographic core. It alone borders on every other Central Asian Republic (ibid).

It is the region's leading military power, the only country in the region that has a manufacturing sector with an important engineering component, and the only one that competes in any way with Russia in influencing regional affairs. Uzbekistan covers a predominantly arid area of about 172,700 square miles (447,400 sq km).

Fergana Valley, is the most densely populated part of both Uzbekistan and the whole of Central Asia. Uzbekistan is bordered to the north and West for 1,368 miles $(2,203 \mathrm{~km})$ by Kazakhstan. About 130 miles $(209 \mathrm{~km})$ of that long border crosses the Aral sea along a northwest to southeast diagonal (Kort,113). To Uzbekistan's south, across a border 1,007 miles $(1,621 \mathrm{~km})$ long is, Turkmenistan. A small stretch of that border in the west crosses the northern edge of Lake Saryqamysh, a huge, salty, and polluted puddle in a desert depression created in the 1960s by drainage from land irrigated by water from the Amy Darya.

At the opposite end of the country, Uzbekistan has a short southern border with Afghanistan. To the east, across a jagged and complicated border that twists, turns, and juts for more than 1,400 miles $(2,260 \mathrm{~km})$, are Tajikistan and Kyrgyzstan. Samarkand is the country's second most important urban centre, after Tashkent. Elsewhere, Bergne $(2007,49)$ writing on Tajikisan says this on Tashkent and 
Uzbekistan: "given that the main cultural and administrative centre in the region is Tashkent, to which republic should it be allocated? Moscow decided in favour of Uzbekistan".

\section{THE UZBEKS AND THEIR LANGUAGE}

According to Kort $(2004,119)$ as of mid-2001, more than 25 million people lived in Uzbekistan. Uzbeks made up about 80 percent of the population. Russians, at 5.5 percent of the population, constituted the largest minority, though about 60,000 of them leave the country each year. Tajiks and Kazakhs respectively made up 5 and 3 percent of the population. With current trends, the Tajiks soon will be the largest ethnic minority in Uzbekistan. The next largest group, a Turkic people, is the Karakalpaks, who make up about 2.5 percent of the population. About 100 tiny ethnic groups make up the rest of the population (119). The Karakalpaks speak a language closer to Kazakh than Uzbek (120). About 88 percent of Uzbekistan's people are Muslims, mainly Sunnis, while 9 percent are Russian orthodox.

The Turkic languages are spoken over a large geographical area in Europe and Asia. It is spoken in the Azeri, the Türkmen, the Tartar, the Uzbek, the Baskurti, the Nogay, the Kyrgyz, the Kazakh, the Yakuti, the Cuvas and other dialects ${ }^{1}$. Uzbek is a Turkic language. It is the official language in Uzbekistan. It is a minority language in Afghanistan, Kyrgyzstan, Kazakhstan, Turkmenistan, Tajikistan, Russia, Turkey, and Xinjiang, China ${ }^{2}$.

Uzbek as a Turkic language shares its roots and base features with languages such as Turkish, Tartar, Kazakh and especially Uyghur. Uzbek has over the centuries been influenced by Persian, Arabic, and Russian due to a dual Islamic and soviet history. Depending on where Uzbek is spoken, it thus can be written in the Latin, Cyrillic, or Perso-Arabic alphabets. Perhaps at this juncture it will be useful to quote Stinobel (2014) in regard to Uzbek. He says: "I first became interested in Uzbek, because I am fascinated by linguistics and find the Turkic language family to have one of the most unique grammars in the world. I was attracted to Uzbek, because of its use of the Latin alphabet and its lack of vowel harmony. ${ }^{3}$ I explore the question of motivation, might this be a factor for motivation in learning Uzbek as L2.

Notable features of the language that are different from English include Subject-Object-Verb sentence order, vowel harmony ${ }^{4}$, and suffixes/agglutination ${ }^{5}$. However, unlike English or most European languages, Uzbek has highly regular phonetic spelling, no irregular verbs, and is gender neutral. Uzbek belongs to the Qarluq family of Turkic languages and consequently its lexicon and grammar are most closely linked to the Uyghur language, while other influences rose from Persian, Arabic and Russian ${ }^{6}$.

US Embassy in Tashkent published a note found on where it says " Today Uzbek language is taught as a subject in four universities of the US. They are Arizona State University, Michigan State University, Indiana University and the University of Texas at Austin. It is true that the numbers of learners of the Uzbek language is not very large, since Uzbek is rather a new language for the Western world." The article continues, "Nowadays, students and even, some professors in US universities became committed to learn Uzbek for very different reasons. Some of them began learning it purely accidentally, while others linked the reason to their work in near future, in which they believe, they might need it.

\footnotetext{
${ }^{1}$ See www.turkishculture.org/literature/language-124.htm. (Accessed on 18/5/2016)

${ }^{2}$ See (http://m.wikihow.com/Learn-Uzbek. ( Accessed on 18/5/2016)

${ }^{3}$ See https://m.facebook.com/notes/us-embassy-tashkent/why-do-people-learn-uzbek-in-the-us/10152039223361 611/.As (Accessed on 20/5/2016)

${ }^{4}$ There are some scholars who most likely erroneously suggested that Uzbek language has vowel harmony as its feature.This is not true of Uzbek language. There is no vowel harmony in the language. The views can be found online: http://m.wikihow.com/Learn-Uzbek.

${ }^{5}$ See http://m.wikihow.com/Learn-Uzbek.

6 See https://m.facebook.com/notes/us-embassy-tashkent/why-do-people-learn-uzbek-in-the-us/101520392233 $61611 /$
} 


\section{Foregrounding Statement of THe Problem}

I must bring to attention that materials for teaching the Uzbek language are scarce and are not as numerous as in other languages such as English, Russian and Chinese. The history of Uzbekistan shades some light why this is so. Instructors of the Uzbek language put extra method in the improvisation of strategies and approaches during the teaching of the Uzbek language. Below I try to trace some historical occurrences that brought forth this situation.

Keller $(2007,250)$ states that "The daily routine of schools creates a sense of national identity, of cultural continuity through time, and of loyalty to the state". She adds that "Children learn proper behaviour and thoughts as they read, take tests, and have class discussions" (250). "Clubs and silly games are as important as studying and literature in shaping a sense of citizenship, because they train children in ways of thinking and patterns of behaviour in a low-key way" (250). Schools are also local models of society, where students' interactions with teachers and with each other reflect social and political tensions around them (250).

A central pedagogical institute for training Uzbek teachers opened in Tashkent in 1935 and was soon joined by branch institutes in Bukhara, Andijon, Termez and other cities according to Keller (2007, 254). In Central Asia, to create a good, Communist school system, the Soviet government needed to train secular teachers and write text books in multiple language (253).

Typical of the chaos of the First Five Year Plan period, Soviet officials were changing the alphabet of the Uzbek language at the same time they were requiring Uzbeks to rapidly enroll all children in primary schools that had not yet been built or staffed. In 1923, as part of a drive to improve general literacy, Turkic intellectual, with Soviet State support, had implemented a simplified version of the centuries old Perso-Arabic script used for central Asian languages, which only scholars could read.

Beginning in 1927, the government converted Turkic and Tajik languages to a Latin based alphabet, partly on the grounds that Latin characters were easier to learn, to read than Arabic ones, and partly to make it harder for people to read Islamic texts. The change meant that the few Uzbek school textbooks that had been printed had to be scrapped and replaced with the books written in the new alphabet (254). Textbooks are certainly not the only way to teach. From the early 1950s students created classroom exhibits, including models, panoramas, small monuments, and newspapers posted on the walls (258).

From the above, I can derive a systematic distortion of learning system which played a key role in scattering stability in the teaching of the Uzbek language. This therefore means that it was difficult for publishers to stock adequate materials or even keep materials for fear of having a dead stock and large stock pile of obsolete materials.

\section{BACKGROUND OF L1 TO L2 ACQUISITION}

Bhatia and Ritchie $(1996,1)$ discuss the phenomena of second (third, fourth, etc) language acquisition (SLA) and use and the interpretation of these phenomena have come to occupy an important place in the development of our understanding of the human capacity for language. By SLA, they say, "we mean the acquisition of a language after the native language has already become established in the individual" (1). The second language (L2) learner thus differs from the first language (L1) learner in two critical ways: (a) the L2 learner begins the process of acquisition at a time when he or she has matured past the age when the L2 is normally acquired, and (b) the L2 learner has a language system in place (1). The domain of a L2 acquisition theory is not the behaviour of speakers (linguistic performance), but rather the mental system (competence) underlying that behaviour (53). Baldwin and Fleming $(2003$, 9) on their part stress about a strategy where teaching a language is an inclusive, social, group activity that invites emotional engagement. They add that it provides powerful context for speaking and listening.

Also it generates real opportunities for speaking and discussion in role as well as shared writing in role with the teacher as scribe. It motivates children to extend their use of language and to try saying and doing things that are the edge of their existing competencies (9). Some possible drama activities include telephone conversation and improvisation, storytelling and active storytelling, and still images.

As a matter of fact, English language and Uzbek are used pari passu during language instruction. 
Again, there are always critical times when you need to grasp some basic knowledge of the Korean language for the successful implementation of L2 during the learning process. In this regard, Keller $(2010,207)$ discusses first language controversy by questioning whether the use of the mother tongue has a positive or negative influence upon the learning of a foreign language at intermediate level. $\mathrm{He}$ says: "Throughout the history of learning a foreign language, one of the most controversial issues has been whether the mother tongue plays a positive or negative role in the learning process.

He adds: "Having worked in South East Asia for over many years as a foreign language instructor, I often received conflicting advice about whether or not the first language should be used when teaching a foreign language. Many experienced educators suggested that the first language should not be used at all, whilst others insisted that it has an important and beneficial role to play throughout the learning process (207-208). In the following section, part of my discussion is derived from the above gloss.

\subsection{Contrastive Hypothesis}

Rehearsing Keller's views, Nunan $(1996,349)$ says L2 acquisition research is concerned with investigating the processes and stages that learners undergo in acquiring L2s and subsequent languages. He adds that the research can be concerned with acquisition in naturalistic environments ( that is where the learner is attempting to acquire the language without formal instruction), acquisition in tutored environments, and acquisition in mixed environments (350).

The field of L2 acquisition was largely created from a line of inquiry known as contrastive analysis. The central question investigated by contrastive analysis was, what is the role of the first language (L1) in the acquisition of an L2 or subsequent language? In the early stages of the development of L2 acquisition as a field of research, it was believed that the development of an L2 was strongly influenced by the learner's L1. This belief was enshrined in the "contrastive hypothesis."

This hypothesis predicts that where L1 and L2 rules are in conflict, then errors are likely to occur, these errors being result of interference between the L1 and L2 (350). According to this hypothesis, L1 learners (Korean students) will tend, when learning Uzbek, to place the nouns after the adjective, just the same way it is in Korean. This is very common in many languages but it is not universal. But why do I mention this grammatical behaviour in both Uzbek and Korean languages? This has an added advantage over L2 acquisition. If it was the opposite, such an error will result to negative transfer of the L1 rule to the L2 rendering L2 difficult to learn. When the rules are similar for both languages, positive transfer will occur and language learning will be facilitated. Where a target language (TL) feature does not exist in the L1, learning will also be impeded.

\subsubsection{Socio-Psychological Theory and the Critical Period Hypothesis}

I strongly am of the view that language can be learnt regardless of the age and this is the idea inculcated to the Korean students learning the Uzbek language. Furthermore, the students have varied reasons why they study Uzbek. Cameron $(2001,11)$ mentions "The Critical Period Hypothesis" which he says is the name given to the idea that young children can learn a second language particularly effectively before puberty because their brains are still able to use the mechanisms that assisted first language acquisition.

In this regard, it is worthwhile to mention Baker $(1993,89)$ who observes that attitudes and motivation are key in learning L2. He says that another popular explanation of failure to learn a second language (or of success in learning) is attitudes and motivation. What are the motives for learning a second language? Are the motives economic, cultural, social, vocational, integrative or for self esteem and self actualization? Learners' sometimes want to affiliate with a different language community. Such learners wished to join in with the majority or majority language cultural activities find their roots or form friendships. This is termed integrative motivation (90).

In the same vein, Lambert (1974) provides socio-psychological theory which combines both the individual and societal elements of bilingualism and is presented in the diagram below. 


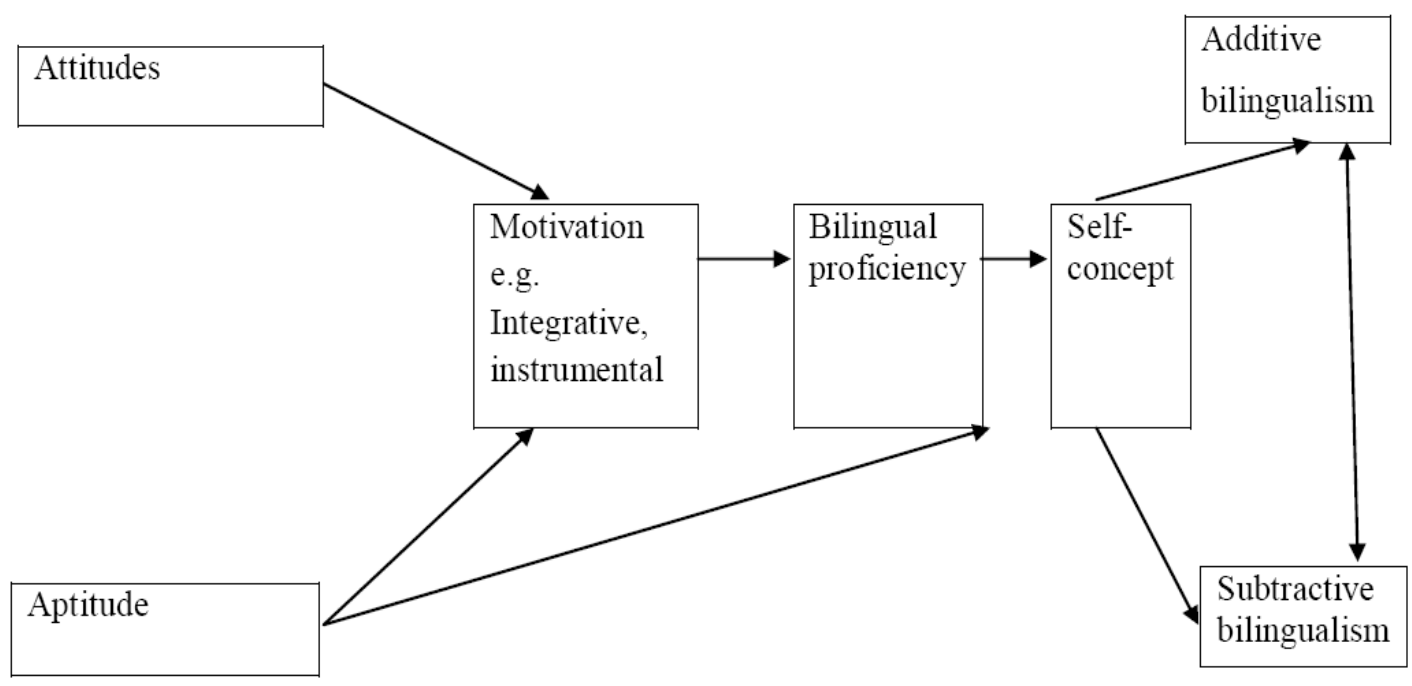

Source: Baker (1993, 94).

The model starts with an individual's attitudes and aptitude towards a language. Next part is motivation - the readiness to engage in language learning or activity. The third part of the model is a person's bilingual proficiency. The factor that comes after bilingual proficiency is self concept. The model finishes with alternative outcome: The model contains the basic ingredients that help make up an explanation of individual and societal bilingualism. It suggests that both individual and sociocultural factors are important in the possession and passage of bilingualism. Like most models, it is static rather than dynamic. It tends to suggest that there is an easy, functional flow in relationships between the factors. What it may fail to do is to represent the dynamic, ever changing, often conflicting path of bilingualism at an individual and at a societal level.

\section{Culture as a Pedagogical Strategy}

The study of the Uzbek language goes alongside the study of its cultural component. This is critical because apart from understanding and appreciating the culture of the Uzbek people, students build their vocabulary significantly when they process aspects of cultural interaction. This can be achieved at exploring their cultural festivals, embroidery, culinary habits, foods, dress, weddings, songs and performance, mannerisms, ethos and the relationship between men and women in the Uzbek cosmos.

Northrop (2007, 94) gives a demonstration on how in Uzbekistan, as well as Tajikistan and Azerbaijan, they aimed above all at the eradication of the head-to-toe veils that many urban-Muslim women, and girls, over the age of nine or ten, wore in the presence of unrelated men. Uzbek women who considered unveiling (or otherwise cooperated with Soviet activists) faced enormous pressure from their families and neighbours (96). The Koreans students then can learn about the hujum period which was series of policies for the Muslim women to remove their veils.

In the same way, Zanca $(2007,181-191)$ mentions a number of foods in an article Fat and All That: Good Eating the Uzbek Way. For example samsas ${ }^{7}$ (samosas, 181), plov ${ }^{8}$ which he says " we know plov as pilaf, a kind of rice stew...the main ingredients for Uzbeks are rice, carrots, onions, mutton or beef, and plenty of salt and cumin"; khumma ${ }^{9}$ (fritters, 187), manti (steamed dumpling, 190), suzma (sharp white farmer's cheese, 190), $\operatorname{shashlik}^{10}$ (kabob, kebab, 191), dumba (sheep tail fat, 191)... This facilitates appreciation of the Uzbek culture among Korean students and also builds their vocabulary. ${ }^{11}$

\footnotetext{
${ }^{7}$ This is Russian spelling. In Uzbek it is spelled somsa.

${ }^{8}$ This again is Russian but spelled as palov in Uzbek.

${ }^{9}$ In Uzbek, it is spelled as gumma. Khumma is Russian.

${ }^{10}$ In Uzbek the kebab is known as kabob.

${ }^{11}$ Sometimes students may do research on particular lexical items from L1 to L2. Assuming L1 is Korean and L2 is Uzbek, they are likely to get challenges especially when the writers or researchers of the Uzbek culture use Russian spelling to list down Uzbek cultural heritage as opposed to the Uzbek language. This brings to the fore
} 
Also, I use holidays in teaching the Uzbek language. Adams (2007, 199-203) discusses public and private celebrations as part of Uzbekistan's National holidays. He mentions Navruz $^{12}$ (March 21, 199), Ramazon Hayiti (feast at the end of Ramadan, 199). In addition there is Qurbon Hayiti (feast of the sacrifice, 199). He adds: "There are two Hayit holidays celebrated in Uzbekistan: Ramazon Hayiti and Qurbon Hayiti ${ }^{13}$. Ramazon Hayiti is the three day celebration at the end of Ramazon (Ramazan), the month of abstention that celebrates the revelation of the Quran, 199). Also, there is International New Year (Yangi Yil, 1 January), the Zoroastrian New Year on the spring equinox ( Navruz, 21 March) and independence Day (Mustaqillik kuni, 1 September, 200). For example, I teach that around Navruz, you eat sumalak. Sumalak made from flour and wheat juice, is a brown paste the consistency of a thick cake batter that tastes like pleasantry toasted malt (202). The Korean students will solidify the understanding of the Uzbek language by appreciating the culture of L2. In addition, they may find similarities and differences and thereby engage in additional discussion and bring more enthusiasm in the learning process.

\subsection{Class Organization Strategy and Pedagogy}

In this section, I discuss important elements that may facilitate Uzbek language in the classroom. It is my view that the success of Uzbek language learning in the classroom rests upon a number of factors in the classroom situation. I provide a comprehensive method of classroom management. In a number of occasions, students who learn Uzbek are divided in the classroom into various groups. But how do I do this? I use attainment level as a basis for this division and for differentiated approaches in their teaching.

Because of the greater need to maintain individual contact and to supervise groups, it is crucial to move around the class looking at student's work, helping and giving instruction and direction. Another important aspect is to have the student read individually. But what is the aim of having them read individually? Emphasis is discovery-based learning. While rote learning is allowed and has rewards, this is synergized by creative thinking. When teaching Uzbek language, I use questions in a way that built upon student's responses until the desired result is achieved. Rejecting a student' response forthwith impedes language learning.

In the teaching of Uzbek language, I am concerned to encourage creativity and inventiveness, giving clear priority to the understanding of principles and concepts. Suggestions from students are welcomed. Creative writing is consequently an important feature in the teaching of Uzbek language, as well as more emphasis on grammar and analysis of sentence structure, and poetry recitation skills. I also offer students occasional opportunities to work with dictionaries, but especially on definition of words.

In summary, my pedagogy in the process of learning Uzbek language is characterized by an emphasis on the product and also the process of learning. While it is important to uphold neatness and attractive, well-set-out exercise books and impressive pieces of finished work, more stress needs to be laid on the learning process and less on the finished product.

In some cases, I encourage students to work co-operatively for much of the time. This means that students are likely to be free to move around the room, and to seek help from other students' and resources, even outside the classroom. Bumgardner $(1992,5)$ rehearses this view about sharing of writing. She says: "students need access to other students, to share what they write to hear others say, "that's good!" or, "I wish I'd written that!" They "feed" one another good things about what they have written. They come to value what other students write, and see examples of what they themselves might like to write (5). She adds that good writing leads to speaking skills. Students need opportunities to speak in prepared situations and to present their own material. They also need opportunities to think and to speak. We need, therefore, to find ways to make students comfortable with sharing what they write.

the problem facing Uzbek instructors. Authors tend to use Russian more often in transcribing Uzbek data because to them, Russian is widely spoken compared to Uzbek. This obstructs the successful acquisition of L2.

${ }^{12}$ As indicated in fn.12, writers are skewed towards the use of Russian spelling other than Uzbek. In Uzbek, Navruz is Navroz.

${ }^{13}$ Hayit in Uzbek. 
In order to enhance enthusiasm in the learning of the Uzbek language, relations between the teacher and student needs to be warmer and more informal, there is also considerable need of teachers striving to protect and encourage pupils' self-esteem by using praise both of students and their work as positive reinforcements.

Broadfoot and Osborn suggest positive features in teaching such as teacher warmth, sensitivity to pupils, an emphasis on pupils' positive achievement, working towards pupils' achievement of selfcontrol and autonomy (p.72). In addition they say there ought to be more variation of treatment according to pupil needs, more emphasis on teaching for understanding and more concurrent feedback to pupils (p.72).

I would be remiss not to mention Shayer and Adey $(1994,110)$ who observe that the Korean education system shows a strong American influence since many of the training of teachers have themselves had periods of education in the USA (110). The Korean primary school teacher takes responsibility for all the lessons of a grade class for one year but subjects are taught formally with, for instance, one hour of Korean language. (110). Language is learnt through tasks and activities, through conversation, learning new words and grammar. In addition, the students engage in literacy skills and learning through stories and theme-based teaching and learning.

Cameron $(2001,11)$ says that "the central characteristics of foreign language learning lie in the amount and type of exposure to the language: there will be very little experience of the language outside the classroom, and encounters with the language will be through several hours of teaching in a school week. In the case of a global language like English, however, even very young children will encounter the language in use on video, TV, computers and film (11).

Listening and doing, listening and identifying, listening and saying, looking and saying, poems and chants, using dialogues are some of the strategies and approaches I use in the teaching of Uzbek language. Dialogues may offer genuine samples of spoken language; contextualized sentence patterns that are not very like the spoken language; written sentences that resemble what people might say; practice sentence patterns - a grammatical drill in disguise; scripts rather like short theatrical plays. Cameron $(2001,69)$ says "deciding how to use dialogues must take into account what they have to offer and what their limitations are.

Furthermore, Cameron (2001, 84) quoting Hatch and Brown (1995: 372) describes five "essential steps" in vocabulary learning based on research into learner's strategies.

(1) Having sources for encountering new words;

(2) Learning the meaning of the words;

(3) Making, a strong memory connection between the forms and meanings of the words;

(4) Using the words.

(5) Getting a clear image, whether visual or auditory or both, for the forms of the new words;

Again, Cameron, quoting Nation $(1990,51)$ lists basic techniques by which teachers can explain the meaning of new words, all of which can be used in the young learner classroom:

(1) Using an object

(2) Using a cut-out figure

(3) Using gesture

(4) Performing an action

(5) Photographs

(6) Drawings or diagrams on the board

(7) Pictures from books (to these we might see as moving images, from TV, video).

I take good observation of the well-being of my students. Concentration in the classroom may be hampered by some form of sickness and especially those that involve listening (audio) and seeing (visual). This is observed elsewhere by Taylor et al $(1995,26)$ who discuss reading difficulties, instruction and assessment. They say that it is good to take note of any visual problem or auditory. 
They say that "as with visual problems, mild auditory problems may be contributing factor but not a major a cause of reading disability students with severe auditory problems (for example, deafness, severe learning loss), on the other hand, do have difficulties with reading. Students with suspected hearing loss should be referred to the school nurse for auditory screening (26).

Writing on pedagogy, Kelleher (2010,210) discusses ways of facilitating learning by quoting Nunan's five features of communicative language learning

(1) An emphasis on learning to communicate through using the target language.

(2) The introduction of authentic texts into the learning situation

(3) An opportunity for learner's not only to focus on the language but also on the learning process itself.

(4) An enhancement of the learner's own personal experiences as important elements contributing to classroom learning.

(5) An attempt to link classroom language learning with language activities.

The views of Kelleher are important in the successful implementation of a learning process and the teaching of the Uzbek language.

\subsection{Further Uzbek Grammar Approaches}

In this section, I am only mentioning certain aspects of Uzbek grammar that I teach. It must be noted that this is not exhaustive and there are so many other aspects of grammar that are not mentioned here. This is deliberate rather than an omission. Furthermore, the levels of instructions differ from basic, intermediate to advanced levels. And this is only grammar yet there is conversation, cultural and listening, Audio-Visual and language laboratory instructions. Nevertheless, by pointing out the basic grammar, students get a foundation of interacting effectively with other components of the Uzbek language.

In my class instruction, emphasis is mostly geared towards the teaching of cases and forms of the verbs. Particular attention is paid to possessive affixes. This is because in the understanding of the grammar, students ought to learn and appreciate the correct usage of suffixes and prefixes that are attached to nouns. This consequently facilitates them in knowing its possessor just like in the function of possessive adjectives. Different forms are used to distinguish the $1^{\text {st }}, 2^{\text {nd }}, 3^{\text {rd }}$ person singular and plural forms. Korean students do not experience significant difficulties in the understanding of the Uzbek grammar. I normally explain the Uzbek grammatical structure to foreground my lesson. This is followed by drawing parallels with the L2 (Korean language) in an attempt to makes students see points of congruence and divergence. This subsequently facilitates in the understanding of the Uzbek grammar. The grammatical errors are identified and then discussed. Having contextualized bilingual problems emanating from L1 to L2, and making students realize that these are just normal problems in L2 acquisition, the second part focuses on approaches in working on the errors. My Korean students are normally tested on a wide range of basic, intermediate to a little more advanced grammatical factors. My main focus is on those factors that involve functional categories like tense, modals, progressives, topicalization, relative clauses, questions ${ }^{14}$ and negation.

\section{CONCLuSION}

This research essay has attempted to demonstrate how effectively the Uzbek language as L2 can be implemented successfully in relation to L1, which in this case is Korean. Specifically, the essay showed how the success of a pedagogy and approach is important in the teaching of L2. In this regard, effective approaches are critical and the instructors must be highly creative to achieve their learning goals.

Clearly, I argue that it is vital that the instructor of L2 should possess some knowledge, albeit basic, of L1. Nevertheless, for adult learners, this is not a conditio sine qua non. The teacher needs to know the $\mathrm{L}$ fairly though. This helps in shading light to more complex language problems.

14 These are similar to the Wh-questions. 
Another point to be noted is that to assist in the effective learning of L2, the instructor must lead the way. For example, he or she needs to demonstrate how to read one section of textbook material at a time. The instructor and the students need to work together through several aspects in the learning process of L2. The instructor should provide instructional support to the extent necessary. For example the students may be given extra clues by their teacher, while also emphasizing on independence practice.

Another point concerns relationship between L1 and L2. In a discipline as large and specialized as modern linguistics, it is perhaps inevitable that the study of various aspects of bilingualism has been parceled out among various sub disciplines and related fields of research. As I had mentioned before, materials and resources on Uzbek language are very sparse. The instructor must go out of his or her ways to be very innovative. The materials found online and those of you tube are not as many compared to the other occidental and oriental languages. There is an urgent need to develop materials for the Uzbek language.

*This article has been funded by Hankuk University of Foreign Studies Research Fund of 2016.

\section{REFERENCES}

Adams, Laura (2007) "Public and private Celebrations: Uzbekistani's National Holidays" in Zanca, Russell and Sahadeo, Jeff (eds) Everyday Life in Central Asia: Past and Present. Bloomington: Indiana University Press.

Baker, Colin (1993) Foundations of Bilingual Education and Bilingualism. Clevedon: Multilingual Matters Ltd.

Baldwin, Patrice \& Fleming, Kate (2003) Teaching Literacy Through Drama: Creative Approaches. New York: Routledge Falmer.

Bergne, Paul (2007) The Birth of Tajikistan. New York: I.B. Tauris and Co. td.

Bhatia, Tej \& Ritchie, William (1996) "Second Language Acquisition: Introduction, Foundations, and Overview" in Bhatia, Tej and Ritchie William (eds) Handbook of Second Language Acquisition. New York: Academic Press.

Broadfoot, Patricia \& Osborn, Marilyn (1993) Perceptions of Teaching. London: Cassell.

Bumgardner, Joyce (1992) Helping Students Learn to Write. Boston. Allyn and Bacon.

Cameron, Lynne (2001) Teaching Languages to Young Learners. Cambridge: Cambridge University Press.

Halliday, M.A.K (2007) Language and Education. London: Continuum.

Jones, B.J. (1987) Korean Phrase Book For Travellers. Seoul: Hollym Publishers.

Kelleher, Mark (2010) "First Language Controversy: Does the Use of the Mother Tongue Have A Positive or Negative Influence Upon the Learning of a Foreign Language at Intermediate Level?" in International Journal of Foreign Studies Vol.2, No.2.

Keller, Shoshana (2007) "Going to School in Uzbekistan" in Zanca, Russell and Sahadeo, Jeff (eds) Everyday Life in Central Asia: Past and Present. Bloomington: Indiana University Press.

Kort, Michael (2004) Central Asia Republics. New York: Infobase Publishing.

Northrop, Douglas (2007) "The Limits of Liberation: Gender, Revolution, and the Veil in Everyday Life in Soviet Uzbekistan" in Zanca, Russell and Sahadeo, Jeff (eds) Everyday Life in Central Asia: Past and Present.Bloomington: Indiana University Press.

Nunan, David (1996) "Issues in Second Language Acquisition Research: Examining Substance and Procedure in Bhatia, Tej and Ritchie William (eds) Handbook of Second Language Acquisition. New York: Academic Press.

Shayer, Michael \& Adey, Philip (1994) Really Raising Standards. London: Routledge.

John Stinobel, (2014) Why Do People Learn Uzbek in the US? https://m.facebook.com/notes/usembassy-tashkent/why-do-people-learn-uzbek-in-the-us/10152039223361611/ (accessed on 20/5/2016)

Taylor, Barbara et al (1995) Reading Difficulties: Instruction and Assessment. New York: McGrawHill, Inc.

Zanca, Russell (2007) "Fat and All That: Good Eating the Uzbek Way" in Zanca, Russell and Sahadeo, Jeff (eds) Everyday Life in Central Asia: Past and Present. Bloomington: Indiana University Press. 
Articles in Webpage and web-blog

www.omniglot.com/language/phrases.uzbek.php (accessed 3/5/2016)

http://m. wikihow.com/Learn-Uzbek (accessed 18/5/2016)

www.turkishculture.org/literature/language-124.htm (accessed 18/5/2016)

https://m.youtube.com/watch?v=NilkjzerPMU (accessed 6/5/2016)

\section{AUTHOR's BIOGRAPHY}

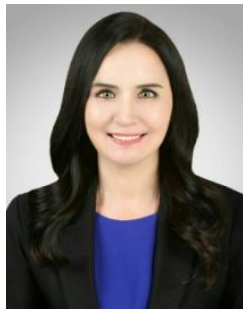

Prof. Aziza Mashrabbekova, holds a $\mathrm{PhD}$ in Philology from the National University of Uzbekistan (2000). She is currently an Associate Professor in the Department of Central Asian Studies, College of International and Area Studies, Hankuk University of Foreign Studies in the Republic of Korea. Her main research interests are in Techniques of teaching foreign language and Comparative linguistics. 